\title{
Caracterização genética de populações naturais de goiabeira serrana (Acca sellowiana) com marcadores microssatélites heterólogos
}

\author{
Karine Louise dos Santos ${ }^{1 *}$ \\ Jean Pierre Henri Joseph Ducroquet ${ }^{1}$ \\ Rubens Onofre Nodari ${ }^{2}$ \\ ${ }^{1}$ Empresa de Pesquisa Agropecuária e Extensão Rural de Santa Catarina \\ Estação Experimental de São Joaquim \\ Caixa Postal 81, CEP 88600-000, São Joaquim - SC, Brasil \\ ${ }^{2}$ Universidade Federal de Santa Catarina, Centro de Ciências Agrárias \\ Departamento de Fitotecnia, PPG em Recursos Genéticos Vegetais \\ Rodovia Admar Gonzaga, 1346, CEP 88034000, Florianópolis - SC, Brasil \\ *Autor para correspondência \\ karinesantos@epagri.sc.gov.br
}

Submetido em 01/02/2011

Aceito para publicação em 19/08/2011

\section{Resumo}

A goiabeira da serra, ou goiabeira serrana (Acca sellowiana), é uma espécie nativa do sul do Brasil e nordeste do Uruguai e devido ao sabor único de seus frutos apresenta-se como alternativa de renda para pequenos agricultores. $\mathrm{O}$ conhecimento da diversidade genética se constitui como uma importante ferramenta para o melhoramento genético e conservação. Com intuito de ampliar o conhecimento a respeito da diversidade genética da espécie, cinco populações naturais de $A$. sellowiana foram analisadas com o uso de iniciadores microssatélites desenvolvidos para o complexo Eucalyptus grandis W. Hill ex Maiden x E. urophylla S.T. Blake. Com a utilização de 10 pares de iniciadores selecionados, 122 plantas foram caracterizadas. Os valores médios para heterozigosidade esperada e observada foram de 0,42 e 0,47 , respectivamente. Os valores estimados para $\hat{\mathrm{f}}$ não diferiram de zero para quatro das cinco populações avaliadas, sugerindo baixo efeito de endogamia. Em média a divergência genética entre populações foi de $\hat{F} s t=0,13$ e $\hat{R} s t=0,14$, em muito devido à incidência de alelos raro ou exclusivos para algumas populações.

Palavras-chave: Feijoa sellowiana, Diversidade genética, Marcadores moleculares, Transferibilidade

\section{Abstract}

Genetic characterization of natural populations of pineapple guava (Acca sellowiana), with heterologous microsatellites markers. Pineapple guava (Acca sellowiana) is a native species from south Brazil and northeast Uruguay, and due to the unique flavor of its fruits, it is an income-generating alternative to small farmers. Knowledge on genetic diversity is an important tool for genetic improvement and conservation. Aiming to increase the knowledge with regarde to the species genetic diversity, five natural populations of $A$. sellowiana were analyzed through microsatellites markers developed from Eucalyptus grandis W. Hill ex Maiden 
x E. urophylla S.T. Blake complex. Using 10 pairs of selected markers, 122 plants were characterized. The mean values for expected and observed heterozigosity were 0.42 and 0.47 , respectively. The $\hat{f}$ estimates did not differ from zero to four out of the five populations evaluated, suggesting a small inbreeding effect. In addition, private alleles and high genetic divergence was observed. the average genetic divergence among the populations was $\hat{\mathrm{F}} \mathrm{st}=0,13$ e $\hat{\mathrm{R}} \mathrm{st}=0,14$, mostly due to the incidenceof rare or exclusive alleles among some populations.

Key words: Feijoa sellowiana, Genetic diversity, Molecular markers, Transferability

\section{Introdução}

A goiabeira-serrana (Acca sellowiana [Berg.] Burret, sinônimo Feijoa sellowiana) também conhecida popularmente no Brasil pelos nomes de goiabeira-do-mato, goiabeira-da-serra ou feijoa, pertence à família Myrtaceae, sendo nativa do planalto meridional brasileiro e nordeste do Uruguai (DUCROQUET et al., 2000; THORP; BIELESKI, 2002). Devido ao potencial organoléptico de seus frutos, a espécie vem recebendo atenção de mercados internacionais como Nova Zelândia e Colômbia (THORP; BIELESKI, 2002). No Brasil, as pesquisas experimentais iniciadas em 1986 (DUCROQUET et al., 2000) foram estimuladas pelo potencial organoléptico, mas também pelo fato da espécie ser adaptada às condições edafoclimáticas das regiões de altitude (superior a $800 \mathrm{~m}$ ) presentes no Sul do Brasil, (LEGRAND; KLEIN, 1977; DUCROQUET et al., 2000); estas características favorecem seu uso como alternativa de renda a agricultores locais.

Os estudos desenvolvidos até o presente buscam por bases técnicas-científicas que dêem suporte ao seu cultivo comercial, mas também a estratégias de conservação da espécie. Neste cenário, os progressos da biologia molecular vêm proporcionando o desenvolvimento de ferramentas de grande eficiência para as estratégias de conservação in situ e ex situ, bem como a caracterização da diversidade existente com vistas a auxiliar programas de melhoramento genético.

$\mathrm{Na}$ caracterização genética de um grupo de plantas utilizam-se marcadores que proporcionem um alto grau de acesso ao genoma. Em consequência do limitado número de marcadores morfológicos identificados para a A. sellowiana (NODARI et al., 1997), o uso de marcadores moleculares tem fundamental importância na caracterização genética desta.
A variabilidade da goiabeira-serrana vem sendo avaliada no Brasil a partir dos acessos do Banco Ativo de Germoplasma (BAG ${ }^{1}$ ) e de populações naturais pela utilização de descritores morfológicos e marcadores alozímicos, RAPDs e, mais recentemente, microssatélites. A utilização de isoenzimas para a caracterização dos acessos do BAG revelou uma alta variabilidade genética entre estes, com $82 \%$ dos locos sendo polimórficos (NODARI et al., 1997). Os marcadores moleculares do tipo RAPD também vêm revelando alta variabilidade genética. Na Itália, estes marcadores também foram utilizados para discriminar 25 acessos de cultivares de goiabeira-serrana introduzidas naquele país (DETTORI; PALOMBI 2000). Quanto aos marcadores microssatélites, a partir da transferibilidade de marcadores desenvolvidos para o gênero Eucalyptus foi possível aprimorar estimativas de variabilidade genética para A. sellowiana (SANTOS et al., 2007).

Os marcadores baseados em Sequências Simples Repetidas (SSRs), ou microssatélites, apresentamse amplamente distribuídos no genoma permitindo ampla cobertura genética, de expressão codominante, multialélico e de grande conteúdo informativo. Estas características fazem com que os marcadores baseados em SSRs sejam ideais para mapeamento genético e físico de genomas, para identificação e discriminação de genótipos e para os estudos de variabilidade genética e estrutura genética de populações (CHAMBERS; MACAVOY, 2000).

Outros trabalhos revelam a abundância destes marcadores também em Eucalyptus spp. onde eles são altamente informativos para o mapeamento ou identificação individual, sendo também eficientes em

O referido Banco Ativo de Germoplasma é mantido pela Empresa de Pesquisa Agropecuária e Extensão Rural de Santa Catarina - Epagri na Estação Experimental de São Joaquim-SC, Brasil. 
mais de uma espécie do mesmo gênero (BRONDANI et al., 1998).

A conservação de sítios de microssatélites entre espécies relacionadas torna possível, em alguns casos, a transferência destes marcadores SSRs para outras espécies (DARVIERWALA et al., 2000; SCOTT et al., 2003). Estudos prévios no Laboratório de Fisiologia do Desenvolvimento e Genética Vegetal/Centro de Ciências Agrárias/Universidade Federal de Santa Catarina confirmaram esta pressuposição e os microssatélites desenvolvidos para o complexo Eucalyptus grandis W. Hill ex Maiden x E. urophylla S.T. Blake amplificam DNA de goiabeira-serrana e permitem melhor caracterização genética da espécie se comparados aos resultados obtidos por marcadores RAPD (SANTOS et al., 2007).

Neste contexto, o presente trabalho objetivou avançar no conhecimento acerca da variabilidade e estrutura genética existente em cinco populações naturais de Acca sellowiana, com o uso de marcadores moleculares microssatélites.

\section{Material e Métodos}

Foram utilizados 10 pares de iniciadores microssatélites desenvolvidos por Brondani et al. (1998) para o complexo Eucalyptus grandis $x$ E. urophylla (a citar EMBRA 26, 69, 85, 99, 108, 123, 148, 166, 267 e 268). O protocolo para amplificação a partir do uso destes iniciadores foi otimizado em estudos prévios sobre a diversidade genética existente no Banco Ativo de Germoplasma e entre cruzamentos de Acca sellowiana (SANTOS et al., 2007).

Salienta-se que embora atualmente se disponham de marcadores específicos desenvolvidos para a espécie em questão (SANTOS et al., 2008), ainda não se dispõem de dados a respeito da diversidade genética de populações naturais com o uso dos mesmos. Neste sentido, justificase a apresentação de dados gerados a partir do uso dos marcadores desenvolvidos para o complexo Eucalyptus, uma vez que este é o primeiro e único conjunto de dados até o momento de realização deste trabalho que permite gerar estimativas da diversidade genética de populações naturais de $A$. sellowiana.
Das cinco populações de ocorrência natural estudadas, três foram coletadas no município de Urubici (SC), (nas comunidades de Santa Bárbara, Jararaca e Rio Cachimbo), uma no município de Lebon Régis (SC), e outra em Erechim (RS). As áreas de coleta estão compreendidas em regiões com altitude média variando de 950m (Urubici - SC e Lébon Régis - SC) até 780m (Erechim-RS) (Tabela 1). A amostragem foi feita de forma aleatória, procurando evitar a coleta de amostras de plantas com distância inferior a $50 \mathrm{~m}$.

TABELA 1: Coordenadas geográficas de coleta de cinco populações de Acca sellowiana Berg. Burret (Myrtaceae) caracterizadas geneticamente.

\begin{tabular}{cccc}
\hline População & Altitude (m) & Latitude & Longitude \\
\hline Santa Bárbara & 1400 & $-28^{\circ} 10^{\prime} 12^{\prime \prime}$ & $-49^{\circ} 35^{\prime} 58^{\prime \prime}$ \\
Jararaca & 1350 & $-28^{\circ} 04^{\prime} 20^{\prime \prime}$ & $-49^{\circ} 31^{\prime} 36^{\prime \prime}$ \\
Rio Cachimbo & 950 & $-28^{\circ} 02^{\prime} 28^{\prime \prime}$ & $-49^{\circ} 28^{\prime} 28^{\prime \prime}$ \\
Lebon Regis & 1200 & $-26^{\circ} 50^{\prime} 58^{\prime \prime}$ & $-50^{\circ} 39^{\prime} 11^{\prime \prime}$ \\
Erechim & 800 & $-27^{\circ} 37^{\prime} 30^{\prime \prime}$ & $-52^{\circ} 17^{\prime} 13^{\prime \prime}$ \\
\hline
\end{tabular}

Latitude e Longitude equivalentes ao ponto central da área de coleta em cada população.

Para obtenção de material vegetal foram coletados de dois a dez frutos por planta, e de três a cinco sementes por planta foram germinadas com intuito de obter ao menos uma plântula procedente de cada planta amostrada a campo. As sementes foram acondicionadas em caixas "Gerbox", contendo papel filtro estéril, embebido em água destilada, em câmara com iluminação permanente e temperatura de $25^{\circ} \mathrm{C} \pm 1$. Foram obtidas em média 25 plântulas por população, totalizando 122 amostras. A extração de DNA foi realizada utilizando-se o método proposto por Doyle e Doyle (1987). O DNA foi quantificado e a sua qualidade avaliada por meio de comparação com DNA de fago $\lambda$, com concentração conhecida, após eletroforese em tampão TBE $1 \mathrm{X}$ em gel de agarose $0,8 \%$ corado com brometo de etídio.

Com vistas a amplificar in vitro as sequências de DNA de interesse, no caso as regiões com sequências repetidas (microssatélites), foram realizadas reações de amplificação (PCR - Polymerase Chain Reaction). A reação de PCR é baseada no anelamento e extensão de uma sequência de DNA alvo, sendo que a delimitação desta 
sequência se dá por meio do uso de oligonucleotídeos ou "inciadores" (primers). Estes iniciadores são sintetizados de forma que sua sequência de nucleotídeos seja complementar àquela que flanqueia a região de interesse (FERREIRA; GRATTAPAGLIA, 1998).

Para tanto, foram realizadas reações com volume total de 13 ul consistindo dos reagentes e a concentração final de: DMSO 5\%, Tampão $3,46 \mathrm{mM}(10 \mathrm{mM}$ Tris$\mathrm{HCl} \mathrm{pH} \mathrm{8,3;50mM} \mathrm{KCl} \mathrm{e} 1,5 \mathrm{mM} \mathrm{MgCl}_{2}$ ), dNTPs $0,02 \mathrm{mM}, \mathrm{Taq}$ polimerase $1 \mathrm{U}$, iniciador $0,3 \mu \mathrm{M}$ e DNA 0,7 ng. O programa de amplificação foi realizado em termociclador MJ Research PT-100 sob as seguintes condições: $96^{\circ} \mathrm{C}$ por $2 \mathrm{~min} ; 30$ ciclos de $94^{\circ} \mathrm{C}$ por $1 \mathrm{~min}, 56^{\circ} \mathrm{C}$ por $1 \mathrm{~min}$ e, $72^{\circ} \mathrm{C}$ por $1 \mathrm{~min}$; o passo de extensão final consistiu de $7 \mathrm{~min}$ a $72^{\circ} \mathrm{C}$. Os produtos da amplificação foram submetidos à eletroforese em gel desnaturante de poliacrilamida $6 \%$ sob as condições de $65 \mathrm{~W}$ por uma hora em tampão $1 \mathrm{X}$ TBE sendo, posteriormente corado com nitrato de prata (CRESTE et al., 2001). Para a observação do padrão de bandas, os tamanhos dos fragmentos foram estimados por comparação com padrões obtidos com DNA ladder 10-bp (Gibco BRL).

A interpretação dos géis permitiu a genotipagem de cada indivíduo, possibilitando estimar parâmetros que caracterizam a variabilidade e estrutura genética. A identificação de erros de genotipagem, devido à existência de alelos nulos e a erros na interpretação dos géis, bem como o ajuste das frequências alélicas quando necessário, foi realizado com uso do programa Micro-Checker Versão 2.2.3 (VAN OOSTERHOUT et al., 2004). A frequência de alelos nulos em cada loco foi estimada como em Brookfield (1996), usando o estimador número 1 :

$$
\hat{\mathrm{r}}=\left(\hat{\mathrm{H}}_{\mathrm{e}}-\hat{\mathrm{H}}_{\mathrm{o}}\right) /\left(1+\hat{\mathrm{H}}_{\mathrm{e}}\right) \text {. }
$$

A partir dos dados gerados foi possível estimar a variabilidade genética de cada população com base nas estimativas das frequências alélicas, heterozigosi dade média observada $\left(\hat{\mathrm{H}}_{0}\right)$, heterozigosidade esperada $\left(\hat{\mathrm{H}}_{\mathrm{e}}\right)(\mathrm{NEI}, 1978)$, número médio de alelos por loco $(\hat{\mathrm{A}})$, porcentagem de locos polimórficos $(\mathrm{P})$ (Critério $99 \%)$, índice de fixação dado por: $\hat{\mathrm{f}}=1-\hat{\mathrm{H}}_{\mathrm{o}} / \hat{\mathrm{H}}_{\mathrm{e}}$; e distância genética (NEI, 1978). Para verificar se os valores médios dos índices de fixação eram diferentes de zero, estimou-se o intervalo de confiança a $99 \%$ de probabilidade com 10 mil reamostragens sobre os locos. Estas estimativas foram obtidas com auxílio do programa GDA (LEWIS; ZAYKIN, 2001). A estimativa da divergência genética entre populações R̂st (SLATKIN, 1995) e Fst (WRIGHT, 1951) foram obtidas com o auxílio do programa GenAlEx 6.1 (PEAKALL; SMOUSE, 2006); sendo que a significância de cada valor de R̂st foi testado com 9.999 permutações.

Estimativas adicionais da diferenciação genética entre as populações foram obtidas pelo procedimento da análise de variância molecular (AMOVA) (MICHALAKIS; EXCOFFIER, 1996). A análise toma por base a matriz de distância entre pares de indivíduos baseado na estimativa Rst, sendo obtida pela soma de quadrados dos desvios totais $\left(\mathrm{SQD}_{\mathrm{T}}\right)$, entre populações $\left(\mathrm{SQD}_{\mathrm{EP}}\right)$, entre indivíduos dentro da população $\left(\mathrm{SQD}_{\mathrm{EI} / \mathrm{DP}}\right)$ e dentro de indivíduos $\left(\mathrm{SQD}_{\mathrm{DI}}\right)$. A análise foi realizada com auxílio do programa GenALEx 6.1 (PEAKALL; SMOUSE, 2006) com a significância de cada valor testado com 999 permutações.

As estimativas do fluxo gênico aparente entre as populações foram obtidas segundo a equação proposta por Crow e Aoki (1984) onde número de migrantes:

$\hat{\mathrm{Nm}}=[(1 / \hat{\mathrm{F} s t})-1] / 4 \alpha$, em que:

$\alpha=[\mathrm{n} /(\mathrm{n}-1)]^{2}$, sendo $\mathrm{n}$ o número de populações. $\mathrm{O}$

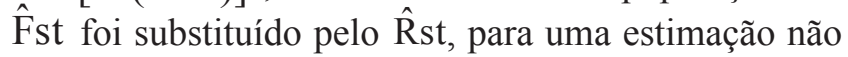
viesada do fluxo gênico.

O tamanho da vizinhança foi estimado por:

$$
\hat{\mathrm{N}}_{\mathrm{b}}=2 \pi \hat{\mathrm{N} m} .
$$

Para a estimativa do tamanho efetivo populacional foi utilizada equação proposta por Li (1976):

$\hat{\mathrm{N}}_{\mathrm{e}}=\mathrm{n} /(1+\hat{\mathrm{f}})$, em que $\mathrm{n}$ é o número de indivíduos analisados na população e $\hat{f}$ o índice de fixação.

Como medida de distância genética entre os pares de populações foi utilizada a distância genética de Nei (1978). A partir destas estimativas foi construído dendrograma, utilizando o método UPGMA(Unweighted 
Pair Group Method Arithmetic Average), sendo que a consistência dos nós foi avaliada por 10.000 reamostragens "bootstrap" sobre locos, com uso do software BOOD v. 2.0 (COELHO, 2000).

\section{Resultados e Discussão}

A partir da caracterização de 122 acessos, oriundos das populações naturais, foram encontrados 43 alelos com pesos moleculares variando de 320 a 120 pares de base. Em trabalho, com os mesmos pares de iniciadores, à exceção de EMBRA 267, porém, de natureza distinta por envolver (119) acessos de Acca sellowiana provenientes do Banco Ativo de Germoplasma (BAG) foram encontrados 49 alelos (SANTOS et al., 2007).

Com exceção da população de Lebon Regis, as demais populações apresentaram ao menos um loco com frequência significativa de alelos nulos. Com o objetivo de minimizar possíveis erros associados à presença desses alelos, as frequências alélicas foram ajustadas nos locos que apresentaram frequência estatisticamente significativa $(\mathrm{P}<0,05)$ (Tabela 2$)$.

Foram observados dois alelos exclusivos para a população de Santa Bárbara (EMBRA123 e 148), com frequências de 0,16 e 0,18 , respectivamente; e outro alelo exclusivo para a população de Lebon Regis (loco EMBRA85) com frequência de 0,02.

A incidência de alelos pouco frequentes $(\mathrm{F}<0,05)$ foi distribuída em acessos oriundos das diferentes populações (Tabela 3).

A incidência de alelos raros nas cinco populações estudadas, adicionado ao fato de terem sido observados alelos exclusivos, sugere que a variabilidade apresentase também dispersa, tornando estas populações complementares quanto à manutenção da diversidade genética da espécie.

Nas populações Santa Bárbara, Erechim e Jararaca o loco EMBRA267 apresentou-se monomórfico; enquanto que na população de Lebon Regis foi o loco EMBRA99 que se apresentou monomórfico. Para a população Rio Cachimbo todos os locos foram polimórficos, porém foi a população que apresentou o menor número de alelos.
TABELA 2: Frequência de alelos nulos em cada loco, para cinco populações naturais de Acca sellowiana Berg. Burret (Myrtaceae) caracterizadas a partir de 10 iniciadores microssatélites do gênero Eucalyptus. (SB: Santa Bárbara, ER: Erechim, JR: Jararaca, LR: Lebon Régis e RC: Rio Cachimbo).

\begin{tabular}{cccccc}
\hline Locos & SB & JR & RC & LR & ER \\
\hline EMBRA26 & 0,0898 & 0,0413 & 0,0468 & $-0,0442$ & 0,1043 \\
EMBRA69 & $0,2955^{*}$ & $0,2637^{*}$ & $-0,1962$ & $-0,0491$ & $0,3628^{*}$ \\
EMBRA85 & 0,0906 & $0,1925^{*}$ & $-0,2226$ & $-0,2824$ & 0,0765 \\
EMBRA99 & $0,137^{*}$ & 0,0912 & $-0,1079$ & $-0,1429$ & 0,0251 \\
EMBRA108 & $-0,0112$ & 0,1998 & 0,084 & 0,0748 & $-0,0858$ \\
EMBRA123 & 0,1039 & 0,021 & 0,0609 & 0,0945 & $0,1828^{*}$ \\
EMBRA148 & 0,0519 & $0,1849^{*}$ & $-0,0109$ & 0 & 0,0732 \\
EMBRA166 & 0,0565 & 0 & $-0,0435$ & $-0,0142$ & $-0,0909$ \\
EMBRA267 & 0 & 0 & $-0,0824$ & 0,025 & 0 \\
EMBRA268 & $-0,1328$ & $-0,0046$ & $0,2461^{*}$ & 0,025 & 0,0877 \\
\hline
\end{tabular}

Estimador número 1 Brookfield (1996); * = significativo a 5\%.

O número médio de alelos observado nas populações naturais foi de 3,5 variando de 2,9 a 4,1. Aparentemente este número pode parecer baixo em se tratando de marcadores microssatélites, porém há de se considerar que os marcadores foram desenvolvidos para um gênero de Myrtaceae distante do gênero Acca. Em estudo similar realizado por Zucchi et al. (2003) com populações naturais de cagaita (Eugenia dysenterica DC.) outra espécie nativa do Brasil pertencente à família Myrtaceae, ainda que os autores tenham observado número médio de 10,4 alelos, alguns locos também apresentaram menos de cinco alelos amplificados. Salienta-se que embora o trabalho também tenha usado marcadores microssátelites desenvolvidos para o gênero Eucalyptus, não houve nenhum loco em comum aos usados neste estudo.

A estimativa de $\hat{\mathrm{H}}_{\mathrm{e}}$ superior a $\hat{\mathrm{H}}_{0}$ nas populações de Santa Bárbara, Erechim e Jararaca, revelou valor significativo para o índice de fixação somente na população Jararaca, indicando déficit de heterozigotos na mesma (Tabela 3 ).

Os valores de diversidade $\left(\hat{\mathrm{H}}_{\mathrm{e}}\right)$ variando de 0,43 a 0,53 foram obtidos considerando todos os locos, mesmo os não polimórficos (Tabela 3). Em estudo realizado com populações naturais de cagaita, Zucchi et al. (2003) encontraram um valor médio para $\hat{\mathrm{H}}_{\mathrm{e}}$ de 0,442 . 
Considerando que as taxas de polimorfismo (devido a deleções, inclusões ou inversões de nucleotídeos) dos marcadores microssatélites podem adicionar um viés na análise de estrutura populacional, uma vez que diferentes populações podem compartilhar alelos em homoplasia, este trabalho fez uso da estatística R̂st (SLATKIN, 1995), que por levar os efeitos de mutação em consideração, pode ser mais adequado que o uso do F̂st (WRIGHT, 1951) durante a análise da estrutura genética de populações. Por outro lado, quando o processo de mutação envolve mais de uma repetição, o uso do Rst pode ser limitado. Assim, neste trabalho optou-se pelo uso das duas estimativas ( $\hat{R} s t$ e $\hat{F} s t$ ) durante a análise de estrutura genética das populações de A. sellowiana.

Em média a divergência genética entre populações foi de $\hat{\mathrm{F}} \mathrm{st}=0,13$ e $\hat{\mathrm{R} s t}=0,14$. Em termos de distância espacial, embora Lebon Regis e Rio Caximbo estejam agrupadas, estas populações distam em mais de 200km; enquanto que as populações Jararaca e Santa Bárbara localizadas em Urubici-SC, embora tenha sido agrupadas com a população de Erechim-RS distam desta última em mais de $400 \mathrm{~km}$. Assim, a divergência genética observada na população de Santa Bárbara (Tabela 4) provavelmente se deve ao fato de terem sido observados alelos exclusivos com frequência superior a 0,05.

Observa-se também que os valores de F̂st e R̂st foram muito similares, sugerindo que mais estudos são necessários para determinar tendências de diferenciação entre estes índices. Esta mesma tendência foi observada por Zucchi et al. (2003), que obtiveram os valores de $\hat{\mathrm{F}} \mathrm{st}=0,25$ e $\hat{\mathrm{R} s t}=0,27$ para dez populações de $E$. dysenterica.

TABELA 4: Estimativas de divergência genética (R̂st - abaixo da diagonal) e probabilidade correspondente ( $\mathrm{P}$ - acima da diagonal) entre pares de cinco populações de $A c c a$ sellowiana Berg. Burret (Myrtaceae) caracterizadas a partir de 10 iniciadores microssatélites do gênero Eucalyptus.

\begin{tabular}{cccccc}
\hline & $\begin{array}{c}\text { Santa } \\
\text { Bárbara }\end{array}$ & Erechim Jararaca & $\begin{array}{c}\text { Lebon } \\
\text { Régis }\end{array}$ & $\begin{array}{c}\text { Rio } \\
\text { Cachimbo }\end{array}$ \\
\hline $\begin{array}{c}\text { Santa } \\
\text { Bárbara }\end{array}$ & & $*$ & $*$ & $*$ & $*$ \\
Erechim & 0,082 & & - & $*$ & $*$ \\
Jararaca & 0,106 & 0,006 & & $*$ & $*$ \\
$\begin{array}{c}\text { Lebon } \\
\text { Régis } \\
\text { Rio }\end{array}$ & 0,188 & 0,228 & 0,157 & & $*$ \\
Cachimbo & 0,166 & 0,210 & 0,158 & 0,040 & \\
\hline
\end{tabular}

*Significância dos valores de Rst $(\mathrm{P}<0,05)$.

$O$ resultado da divergência genética entre populações está de acordo com o observado para outras espécies arbóreas alógamas, onde a maior variabilidade genética encontra-se dentro das populações, sendo que a divergência entre populações é reduzida de acordo com o aumento do fluxo gênico (LOVELESS; HAMRICK, 1984).

O número de migrantes por geração ( $\hat{\mathrm{N} m})$ foi de 0,98 e o valor para tamanho de vizinhança $\left(\hat{\mathrm{N}}_{\mathrm{b}}\right.$ ) foi estimado em 6,16 , o que indica para as

TABELA 3: Índices de diversidade genética e tamanho efetivo populacional para cinco populações naturais de Acca sellowiana Berg. Burret (Myrtaceae) caracterizadas a partir de 10 iniciadores microssatélites do gênero Eucalyptus.

\begin{tabular}{cccccccc}
\hline População & $\mathrm{n}$ & $\hat{\mathrm{A}}$ & $\begin{array}{c}\mathrm{n}^{\mathrm{o}} \text { de alelos } \\
\text { com } \mathrm{F}<0,05\end{array}$ & $\hat{\mathrm{H}}_{0}$ & $\hat{\mathrm{H}}_{\mathrm{e}}$ & $\hat{\mathrm{f}}_{(\mathrm{IC}) * *}$ & $\hat{\mathrm{N}}_{\mathrm{e}}$ \\
\hline Santa Bárbara & $24,30(1,44)^{*}$ & $4,10(0,77)$ & 10 & $0,42(0,08)$ & $0,53(0,09)$ & $0,21(0,418 ;-0,029)$ & 20,08 \\
Erechim & $17,60(1,76)$ & $3,40(0,56)$ & 2 & $0,38(0,10)$ & $0,53(0,08)$ & $0,26(0,688 ;-0,023)$ & 13,97 \\
Jararaca & $17,60(1,52)$ & $3,60(0,70)$ & 3 & $0,34(0,07)$ & $0,50(0,09)$ & $0,31(0,501 ; 0,139)$ & 13,44 \\
Lebon Régis & $27,30(0,77)$ & $3,30(0,59)$ & 5 & $0,47(0,11)$ & $0,43(0,08)$ & $-0,10(0,188 ;-0,431)$ & 30,33 \\
Rio Cachimbo & $16,40(1,08)$ & $2,90(0,43)$ & 4 & $0,49(0,09)$ & $0,46(0,06)$ & $-0,07(0,281 ;-0,394)$ & 17,63 \\
\hline Média & $20,64(0,85)$ & $3,46(0,27)$ & 5 & $0,42(0,04)$ & $0,48(0,03)$ & $0,14(0,208 ;-0,015)$ & - \\
\hline
\end{tabular}

Número médio de indivíduos genotipados por população (n), número médio de alelos por loco (ÂA), número de alelos com frequência inferior a 0,05 , heterozigosidade observada $\left(\hat{\mathrm{H}}_{0}\right)$ e esperada $\left(\hat{\mathrm{H}}_{\mathrm{e}}\right)$, índice de fixação $(\hat{\mathrm{f}})$ e tamanho efetivo populacional $\left(\hat{\mathrm{N}}_{\mathrm{e}}\right)$. * Valores entre parênteses: Desvio padrão; **intervalo de confiança (IC) a 99\%, obtido por 10.000 reamostragens sobre locos. 
populações em estudo o número de genitores que trocam alelos. Em havendo um número menor do que o encontrado implicaria aumento da divergência entre as vizinhanças, em decorrência do incremento interno dos níveis de endogamia. Segundo Slatkin e Barton (1989), os valores de $\hat{\mathrm{N} m}$ e $\hat{\mathrm{N}}_{\mathrm{b}}$ determinam se a deriva genética, por si só, pode produzir variabilidade genética substancial entre locais. Se estes valores forem superiores a 1,0, então o fluxo gênico é suficiente para prevenir diferenciação devido à deriva genética. Portanto, os valores obtidos neste estudo indicaram que o fluxo gênico está próximo do suficiente para prevenir diferenciação populacional devido à deriva genética nas populações caracterizadas.

Um parâmetro importante nas atividades de conservação in situ é a determinação do tamanho efetivo ( $\hat{\mathrm{N}}_{\mathrm{e}}$ ), uma vez que ele trata da representatividade genética das amostras. Todavia, é preciso considerar que este parâmetro toma como base as estimativas dos índices de fixação para cada população. Neste sentido, as estimativas aqui apresentadas servem como um indicativo da representatividade da amostra caracterizada de cada população.

A partir da estimativa de tamanho efetivo pode-se verificar que a amostragem nas populações de Santa Bárbara, Erechim e Jararaca representam tamanho efetivo inferior ao número de indivíduos amostrados (Tabela 3). Segundo Loveless e Hamrick (1984), quando existe equilíbrio entre os eventos demográficos tais como flutuações temporais no tamanho da população, presença de estruturação e endogamia dentro das populações, diferenças na fertilidade, assincronismo no florescimento, entre outros; os valores de $\hat{\mathrm{N}}_{\mathrm{e}}$ são muito próximos ao número de indivíduos coletados.

No dendrograma observa-se a distribuição das cinco populações, apresentando graus de distância genética variando de 9 a 22\% (Figura 1). As populações de Lebon Regis e Rio Cachimbo foram as que apresentaram maior similaridade, muito provavelmente por apresentarem padrões comuns de distribuição de frequências alélicas em especial para os iniciadores EMBRA123 e 267. Cabe destacar o resultado observado para a população Rio
Cachimbo, que apresentou a maior distância genética com relação às demais populações, podendo esta ser reflexo de uma restrição de fluxo gênico e à deriva genética, o que justificaria o padrão diferenciado de formato e sabor dos frutos observados nesta população. Estudos posteriores poderão correlacionar características fenotípicas à distância entre populações, levando em conta o histórico de manejo e uso.

Os resultados para distância genética de Nei apresentaram maior discrepância com os observados para a divergência genética através da estimativa R̂st, no que se refere à distância entre as populações Jararaca e Erechim. Este fato pode estar associado ao pequeno número de alelos, uma vez que este se constitui em um indicador adequado do coeficiente de variação de estimativas de divergência genética. Assim, o fator que pode estar interferindo na consistência das estimativas de divergência, segundo Kalinowski (2002), pode ser o número total de alelos, sugerindo que a seleção de marcadores para a caracterização de populações naturais da espécie considere locos com maior número de alelos.

As estimativas obtidas para os valores $\hat{f}$ sugerem baixo efeito de endogamia, o que é corroborado pela estimativa do fluxo gênico e de divergência genética entre populações, além da própria distância espacial entre populações.

Níveis consideráveis de diversidade genética em diferentes populações, baixos efeitos de endogamia e os valores obtidos para fluxo gênico e tamanho da vizinhança são características favoráveis à manutenção da diversidade genética das populações estudadas. Todavia, embora existam estudos incipientes sobre a influência das atividades antrópicas não somente de manejo e uso das áreas de ocorrência da espécie, bem como a influência de possíveis estratégias de seleção sobre a espécie (SANTOS et al., 2009), análises ao nível de população que considerem estes efeitos ainda são necessários. 


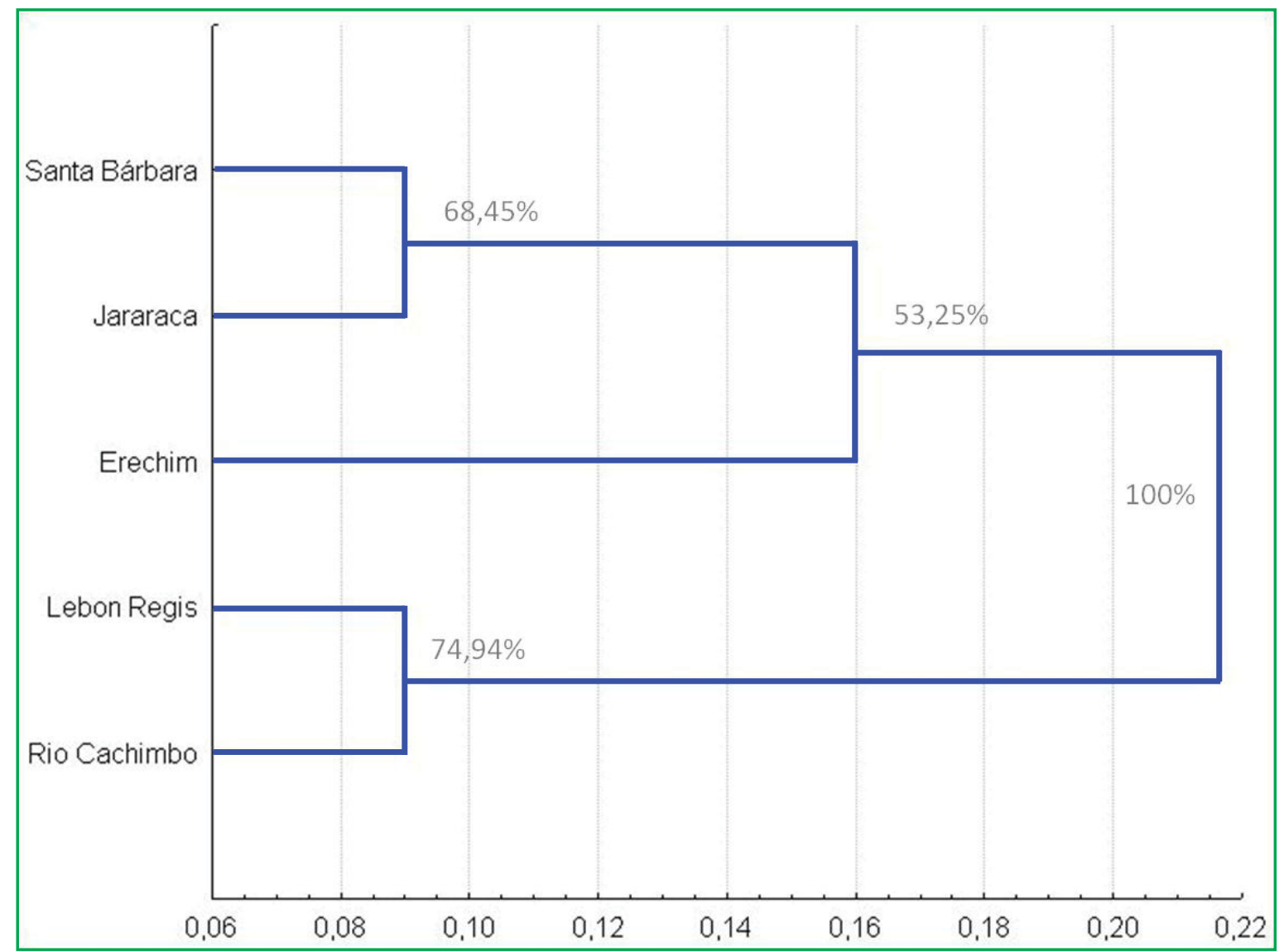

FIGURA 1: Dendrograma obtido por agrupamento UPGMA a partir de distância genética de Nei (1978) com base em 10 marcadores microssatélites do gênero Eucalyptus para cinco populações naturais de Acca sellowiana Berg. Burret (Myrtaceae).

\section{Agradecimentos}

Ao Centro Nacional de Recursos Genéticos e Biotecnologia (Cenargen) pela disponibilidade em ceder os marcadores microssatélites utilizados neste estudo. Ao Conselho Nacional de Desenvolvimento Científico e Tecnológico-CNPq, pelo suporte financeiro. Aos professores Lineu Schneider e Miguel Pedro Guerra pelo auxílio nas coletas a campo. À Adriana Cibele de Mesquita Dantas, pela colaboração durante as atividades de laboratório. E aos agricultores visitados pela cordialidade e auxílio durante as coletas.

\section{Referências}

BRONDANI， R. P. V.; BRONDANI， C.; TARCHINI， R.; GRATTAPAGLIA, D. Development, characterization and mapping of microsatellite markers in Eucalyptus grandis and E. urophylla. Theoretical and Applied Genetics, Berlin, v. 97, p. 816-827, 1998. BROOKFIELD, J. F. Y. A simple new method for estimating null allele frequency from heterozygote deficiency. Molecular Ecology, Vancouver, v. 5, p. 453-455, 1996.

CHAMBERS, G. K.; MACAVOY, E. S. Microsatellites: consensus and controversy. Comparative Biochemistry and Physiology, Salt Lake City, v. 126, p. 455-476, 2000.

COELHO, A. S. G. BOOD v. 2.0. Avaliação de dendrogramas baseados em estimativas de distâncias/similaridades genéticas através do procedimento de bootstrap. Goiânia: Universidade Federal de Goiás, Laboratório de Genética Vegetal, DBG/ICB/ UFG. 2000. CD-ROM.

CRESTE, S.; TULMANN-NETO, A.; FIGUEIRA, A. Detection of single sequence repeat polymorphism in denaturing polyacrylamide sequencing gels by silver staining. Plant Molecular Biology, Zurich, v. 18, p. 1-8, 2001.

CROW, J. F.; AOKI, K. Group selection for polygenic behavioral trait: estimating the degree of population subdivision. Proceedings 
of the National Academy of Sciences of the United States of America, Washington, v. 81, p. 6073-6077, 1984

DARVIERWALA, A. P.; RAMAKRISHNA, W.; RANJEKAR, P. K.; GUPTA, V. S. Sequence variations at a complex microsatellite locus in rice and its conservation in cereals. Theoretical and Applied Genetics, Berlin, v. 101, p. 1231-1298, 2000.

DETTORI, M. T.; PALOMBI, M. A. Identification of Feijoa sellowiana Berg accessions by RAPD markers. Scientia Horticulturae, Amsterdam, v. 86, p. 279-290, 2000.

DOYLE, J. J.; DOYLE, J. L. Isolation of plant DNA from fresh tissue. Focus, v. 12, p. 13-15, 1987.

DUCROQUET, J. P. H. J.; HICKEL, E. R.; NODARI, R. O. Goiabeira-serrana (Feijoa sellowiana). Série Frutas nativas 5; Jaboticabal: Funep, 2000, 66 p.

FERREIRA, M. E.; GRATTAPAGLIA, D. Introdução ao USP de marcadores moleculares em análise genética. 3. ed. Brasília: Embrapa, 1998, 220 p.

LEGRAND, C. D.; KLEIN, R. M. Mirtáceas. In: REITZ, P. R. (Ed.). Flora ilustrada catarinense. Itajaí: SUDESUL, FATMA, HBR, 1977. p. 623-629.

LEWIS, P. O.; ZAYKIN, D. Genetic data analysis: computer program for the analysis of allelic data. Version 1.0 (d16c). 2002. Disponível em: <http://lewis.eeb.uconn.edu/lewishome/software. html>. Acesso em: 20 jan. 2011.

LI, C. C. Population genetics. Chicago: University of Chicago Press, 1976. 366 p.

LOVELESS, M. D.; HAMRICK, J. L. Ecological determinants of genetic structure in plant populations. Annual Review of Ecology and Systematics, Palo Alto, v. 15, p. 65-95, 1984.

KALINOWSKI, S.T. How many alleles per locus should be used to estimate genetic distances? Heredity, Sheffield, v. 88, p. 62-65, 2002.

MICHALAKIS, Y.; EXCOFFIER, L. A generic estimation of population subdivision using distances between alleles with special reference for microsatellite loci. Genetics, Pittsburgh, v. 142, p. 1061-1064, 1996.

NEI, M. Estimation of average heterozygosity and genetic distance from a small number of individuals. Genetics, Pittsburgh, v. 89, p. 583-590, 1978.

NODARI, R. O.; DUCROQUET, J. P; GUERRA, M. P.; MELER, K. Genetic variability of Feijoa sellowiana germplasm. Acta Horticulturae (Proceedings of the International Symposium on Myrtaceae), Leuven, v. 452, p. 41-46, 1997.
PEAKALL, R.; SMOUSE, P. E. GENALEX V6.1: Genetic analysis in Excel. Population genetic software for teaching and research. Molecular Ecology Notes, v. 6, p. 288-295, 2006.

SANTOS, K. L.; WELTER, L. J.; DANTAS, A. C. M.; GUERRA, M. P.; DUCROQUET, J. P. H. J.; NODARI, R. O. Transference of microsatellite markers from Eucalyptus spp. to Acca sellowiana and the successful use of this technique in genetic characterization. Genetics and Molecular Biology, Ribeirão Preto, v. 30, n. 1, p. 73-79, 2007.

SANTOS, K. L.; SANTOS, M. O.; LABORDA, P. R.; SOUZA, A. P., PERONI, N.; NODARI, R. O. Isolation and characterization of microsatellite markers in Acca sellowiana (Berg) Burret. Molecular Ecology Resources, v. 8, p. 998-1000, 2008.

SANTOS, K. L.; PERONI, N.; GURIES, R. P.; NODARI, R. O. Tradicional knowledge and management of feijoa (Acca sellowiana) in southern Brazil. Economic Botany, New York, v. 63, n. 2, p. 204-214, 2009.

SCOTT, L. J.; SHEPHERD, M.; HENRY, R. J. Characterization of highly conserved microsatellite loci in Araucaria cunninghamii and related species. Plant Systematics Evolution, Jena, v. 236, p. 115-123, 2003.

SLATKIN, M. A measure of population subdivision based on microsatellite allele frequencies. Genetics, Pittsburgh, v. 139, p. 457-462, 1995.

SLATKIN, M.; BARTON, N. H. A comparison of three indirect methods for estimating average levels of gene flow. Evolution, New York, v. 43, p. 1349-1368, 1989.

THORP, G.; BIELESKI, R. Feijoas: Origins, Cultivation and Uses. Auckland: HortResearch, 2002. 87 p.

VAN OOSTERHOUT C.; HUTCHINSON W. F.; WILLS, D. P. M.; SHIPLEY, P. Micro-Checker: software for identifying and correcting genotyping errors in microsatellite data. Molecular Ecology Notes, v. 4, p. 535-538, 2004.

WRIGHT, S. The genetical structure of populations. Annals of Eugenics, London, v. 15, p. 323-354, 1951.

ZUCCHI, M. I.; BRONDANI, R. P. V.; PINHEIRO, J. B.; CHAVES, L. J.; COELHO, A. S. G.; VENCOVSKY, R. Genetic structure and gene flow in Eugenia dysenterica DC in the Brazilian Cerrado utilizing SSR markers. Genetics and Molecular Biology, Ribeirão Preto, v. 26, n. 4, p. 449-457, 2003. 